\title{
Multi-objective optimization of a building envelope for thermal performance using genetic algorithms and artificial neural network
}

\author{
D. Gossard, B. Lartigue*, F. Thellier \\ Université Toulouse III - Paul Sabatier, Laboratoire PHASE, 118, route de Narbonne, 31062 Toulouse cedex 9, France
}

\section{A R T I C L E I N F O}

\section{Article history:}

Received 16 May 2013

Received in revised form 31 July 2013

Accepted 18 August 2013

\section{Keywords:}

Multi-objective optimization

Building envelope

Energy performance

Comfort degree

ANN

Genetic algorithm

\begin{abstract}
A B S T R A C T
The objective of this paper is to present a method to optimize the equivalent thermophysical properties of the external walls (thermal conductivity $k_{\text {wall }}$ and volumetric specific heat $(\rho c)_{\text {wall }}$ ) of a dwelling in order to improve its thermal efficiency. Classical optimization involves several dynamic yearly thermal simulations, which are commonly quite time consuming. To reduce the computational requirements, we have adopted a methodology that couples an artificial neural network and the genetic algorithm NSGA-II. This optimization technique has been applied to a dwelling for two French climates, Nancy (continental) and Nice (Mediterranean). We have chosen to characterize the energy performance of the dwelling with two criteria, which are the optimization targets: the annual energy consumption $Q_{T O T}$ and the summer comfort degree $I_{\text {sum. }}$. First, using a design of experiments, we have quantified and analyzed the impact of the variables $k_{\text {wall }}$ and $(\rho c)_{\text {wall }}$ on the objectives $Q_{\text {Tот }}$ and $I_{\text {sum }}$, depending on the climate. Then, the optimal Pareto fronts obtained from the optimization are presented and analyzed. The optimal solutions are compared to those from mono-objective optimization by using an aggregative method and a constraint problem in GenOpt. The comparison clearly shows the importance of performing multiobjective optimization.
\end{abstract}

(c) 2013 Elsevier B.V. All rights reserved.

\section{Introduction}

Considering the present energy balance [1], buildings design has to integrate thermal performance. This notion takes into account energy savings and comfort of the occupants, as the reduction of building energy consumption cannot be achieved at the expense of the indoor environment quality (IEQ). Improving the thermal performance of a building can be done in two ways. The first approach is based on a trial-and-error method. A set of variables corresponding to design building parameters is chosen; several values are picked from this set and are tested. This method can reveal some interesting trends, but it cannot achieve an optimal design without fail. The second approach ensures a more reliable method by using optimization algorithms - we can cite, for example, the study of Tuhus-Dubrow [2] for the optimization of the building shape. However, since in the field of building physics, the objective functions are generally calculated over one year, and because the optimization algorithms require hundreds or thousands of calculations, the total optimization computation duration can quickly become prohibitive. To resolve this computation-time problem, another method exists. It consists of using artificial neural networks (ANN) to evaluate cost functions faster, without degrading their accuracy, by mimicking the behavior of external simulation programs. ANN have proven their efficiency in building physics studies [3-6]. Once validated, the ANN is coupled to a multi-objective algorithm to find the problem's optimal solutions.

The aim of our study is to propose a fast and efficient multiobjective optimization approach to optimize the envelope of a residential building based on its thermal performance. In this respect, our article details the steps of the optimization methodology. The variables calculated in the optimization are the effective thermophysical properties of the external walls (thermal conductivity $k$, and volumetric specific heat $(\rho c)$ ). A discussion is performed to select the most appropriate objective functions that define the thermal performance of the building. In such a problem, with multiple variables and non-linear objective functions, a parametric study is useful to understand the optimization's solutions. Consequently, we have performed a parametric study using a design of experiments that quantifies the impact of the variables on the objective functions. Then, the results of the optimization are presented, as a function of the climate. Last, the methodology is discussed by comparing the results of multi-objective and mono-objective optimizations, demonstrating the limits of the latter. 


\author{
Nomenclature \\ $a_{n} \quad$ principal effect \\ ANN artificial neural network \\ c $\quad$ specific heat $\left(\mathrm{J} \mathrm{kg}^{-1} \mathrm{~K}^{-1}\right)$ \\ $I_{\text {sum }} \quad$ integrated discomfort degree in summer $\left({ }^{\circ} \mathrm{Ch}\right)$ \\ $I_{\text {win }} \quad$ integrated discomfort degree in winter $\left({ }^{\circ} \mathrm{Ch}\right)$ \\ $k$ thermal conductivity $\left(\mathrm{W} \mathrm{m}^{-1} \mathrm{~K}^{-1}\right)$ \\ MSE mean squared error \\ NSGA non-sorted genetic algorithm \\ $p \quad$ number of simulations \\ $P M V$ predicted mean vote \\ $\mathrm{Q}_{\text {TOT }} \quad$ annual energy demand $(\mathrm{kWh})$ \\ $t$ time (s) \\ $T$ temperature $\left({ }^{\circ} \mathrm{C}\right)$ \\ $T_{\text {com }} \quad$ comfort temperature $\left({ }^{\circ} \mathrm{C}\right)$ \\ $T_{\text {in }} \quad$ indoor temperature $\left({ }^{\circ} \mathrm{C}\right)$ \\ $T_{0} \quad$ outside temperature $\left({ }^{\circ} \mathrm{C}\right)$ \\ $x_{n} \quad$ parameter \\ Greek letters \\ $\rho \quad$ density $\left(\mathrm{kg} \mathrm{m}^{-3}\right)$
}

\section{Optimization methodology}

\subsection{Objective-functions and optimization variables}

\subsubsection{Objective-functions}

To perform an optimization problem, the first step is to define the appropriate indicators reflecting the thermal performance of a building. In most studies, building energy savings are calculated by considering annual heating and cooling demands $[7,8]$.

In our study, we consider the annual energy load, $Q_{T O T}$, required to maintain the winter temperature set point to $19^{\circ} \mathrm{C}$ [9] in a freerunning building.

The occupants' thermal comfort can be evaluated in several ways. Based on steady-state heat transfer theory, Fanger's model [10] proposed the Predicted Mean Vote PMV deriving from climatic chamber studies, as a thermal comfort index. Nicol and Humphreys [11] considered the application of the adaptive approach to thermal comfort standards, and presented the relationship between comfort temperature $T_{c o m}$ and outdoor temperature $T_{o}$ for freerunning buildings: $T_{c o m}=13.8+0.54 T_{0}$. De Dear and Brager [12] presented the revisions to ASHRAE Standard 55 for thermal comfort in naturally ventilated buildings, including a new adaptive comfort standard, which allows warmer indoor temperatures for naturally ventilated buildings in summer and in warmer climate zones. Zhang et al. [13] proposed the two parameters $I_{\text {win }}$ and $I_{\text {sum }}$ that measure the thermal comfort degree in an indoor environment. They are defined as integrated discomfort degree for air indoor temperature in winter and in summer, respectively. By definition, the thermal comfort degree increases when $I_{\text {sum }}$ and $I_{\text {win }}$ decreases.

In our study, as we want to characterize summer comfort, we will use the summer thermal comfort index $I_{\text {sum }}$ defined on an entire year as:

$I_{\text {sum }}=\int_{0}^{8760}\left(T_{\text {in }}-T_{\text {com }}\right) d t$

where $T_{\text {in }}$ is the indoor temperature as a function of time; $T_{\text {com }}$ is the comfort temperature fixed at $T_{\text {com }}=28^{\circ} \mathrm{C}$; $d t$ is the time step fixed at $d t=1 \mathrm{~h}, 8760$ is the number of hours in a year.

\subsubsection{Optimization variables}

The optimization variables are the thermophysical properties of the external walls $\left(k_{\text {wall }}\right.$ and $\left.(\rho c)_{\text {wall }}\right)$ and of the roof $\left(k_{\text {roof }}\right.$ and $(\rho c)_{\text {roof }}$ ). Their ranges of variation are respectively $0.05 \leq k \leq 1.175$ $\mathrm{W} \quad \mathrm{m}^{-1} \quad \mathrm{~K}^{-1}$ and $40 \leq(\rho c) \leq 2000 \quad \mathrm{~kJ} \mathrm{~m}^{-3} \quad \mathrm{~K}^{-1}$, which are conventional values for building materials. Optimization variables are considered as continuous variables.

These two objective-functions $\left(Q_{T O T}\right.$ and $\left.I_{\text {sum }}\right)$ are time consuming because they require one-year simulations to be evaluated. Moreover, considering the variables' ranges, a large search space has to be explored extensively. Therefore, we propose a methodology to simplify the optimization.

\subsection{Multi-objective evolutionary algorithm optimization}

Simultaneously reducing the building energy consumption and maintaining a comfortable indoor environment are two conflicting objectives. Since these two functions are nonlinear, stochastic global multi-objective optimization techniques such as genetic algorithms can be used in order to obtain optimal designs $[3,14]$. Genetic algorithms are gradient-free stochastic search methods that mimic natural biological evolution. We used the Nondominated Sorting Genetic Algorithm II, NSGA-II [15]. First, it initializes a random population of several individuals, then it produces offspring by recombination and mutation, evaluates the individuals, and finally selects the fittest ones.

The efficiency of NSGA-II is due to the non-dominated-andcrowding sorting and selection. This method ensures both the convergence of the population and its spreading. It is based on the two following parameters:

- The rank (or fitness) value of an individual. In a population, nondominated individuals have rank 1 and belong to the first front. Individuals that are dominated only by solutions from the first front belong to the second front, and then have rank 2 . The notion of rank enables the comparison of an individual to the whole population. At the end of the optimization process, only the Pareto front with rank 1 is kept.

- The crowding distance of an individual. It measures how close an individual is to its neighbors. A large average crowding distance results in better diversity in the population. Individuals with the highest crowding distances should be preferred for the spreading.

\subsection{Artificial neural network (ANN)}

As we have already written, the calculation of the objective functions based on one-year simulations is relatively slow. In order to make it faster, we use a multilayer feed-forward artificial neural network (ANN). It is composed of layers of neurons: we classically call the layer that produces the network output, the output layer, and all other layers are called hidden layers. Its principle is strongly inspired from the biological nervous system [16]. Neurons may use any differentiable transfer function to generate their output. The performance of the ANN is strongly influenced by the connections between neurons.

The ANN must be trained to perform a specific task by adjusting the weights between neurons. The weights are adjusted by comparison between outputs of ANN and target-values from sampling data sets, until the outputs match the targets.

\subsection{Optimization framework}

The proposed optimization methodology is shown schematically in Fig. 1.

First, a building model is established in TRNSYS [17], which is a software designed for the transient thermal simulation of complex 
1/ ANN Learning

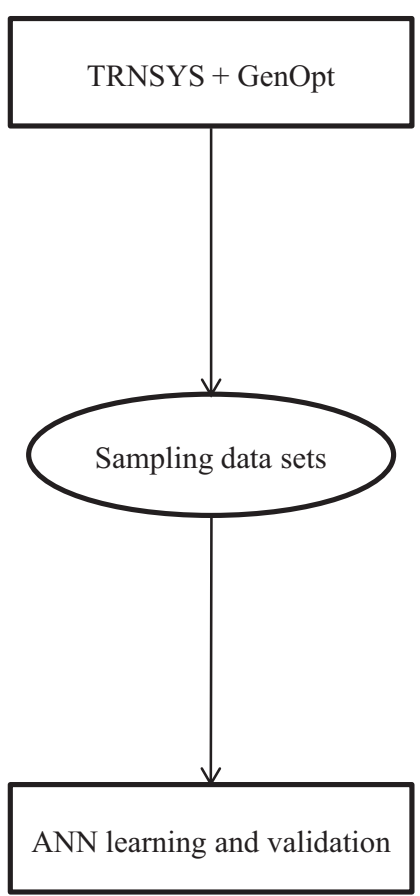

2/ Multi-objective optimization process

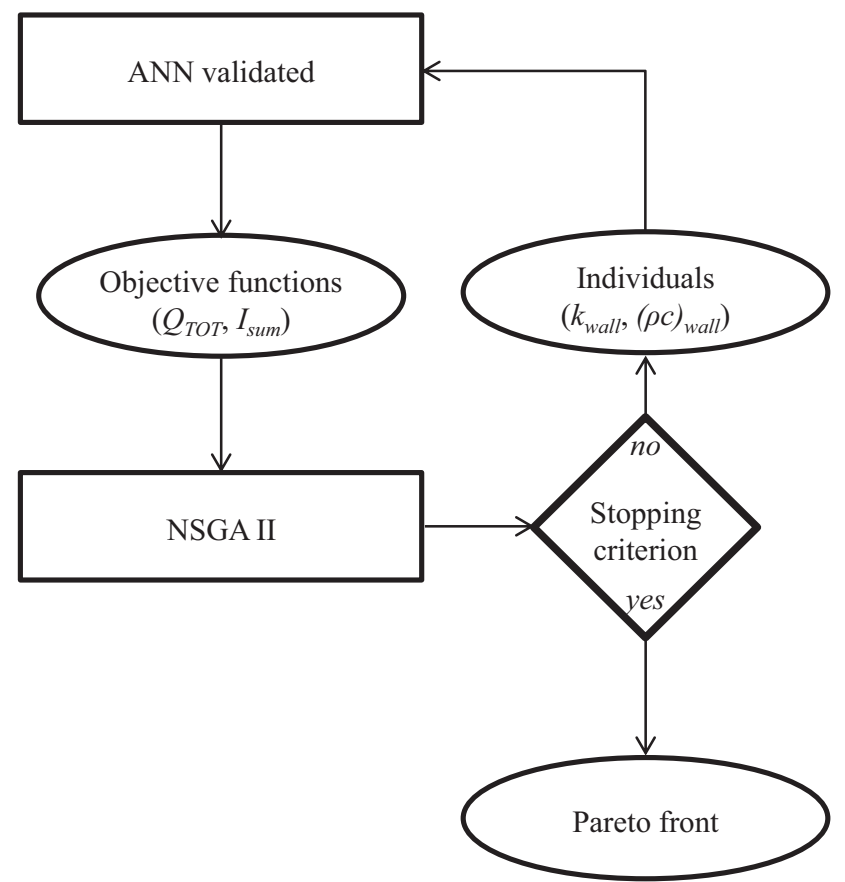

Fig. 1. Optimization framework. systems. Then, a sampling data set of variables $(k, \rho c)$ is generated in order to cover the maximum search space. It is composed of sufficient data randomly distributed over the search space by the software GenOpt [18]. GenOpt performs parametric studies by spanning a multi-dimensional grid in the space of the independent parameters, and it evaluates the objective functions at each grid point.

Once the training and validation are completed, the ANN is ready to perform fast and accurate calculations of objectivefunctions. Finally, NSGA II is coupled to the ANN in order to achieve optimization. NSGA II provides input values to ANN and ANN performs evaluations of objective functions required by the NSGA II.

\section{Application of the optimization methodology to a dwelling}

\subsection{Description of the case study}

The methodology presented above is now applied to a dwelling (Fig. 2), whose specification is detailed in [19]. It is a single storey house with a net floor area of $112 \mathrm{~m}^{2}$ and a ceiling height of $2.3 \mathrm{~m}$. It is divided into 6 thermal zones, 3 of which are heated. Table 1 lists the assumptions and specifications adopted for the thermal simulation of the dwelling.

The inertia of the inner walls is low, so that the inertial effects of the external walls are emphasize more. The external walls are highlighted in red in the blueprint (Fig. 2).

The external envelope is divided into vertical external walls and the roof (Fig. 3). The thermophysical properties of the plaster and the insulation are kept constant during the optimization process and their values are shown in Table 1. Keeping the insulation constant enables to distinguish the insulation function of the wall, from its structural function and to focus of this one.

\subsection{Impact of the variables on the objective-functions}

Before performing the optimization, we need to know the influence of variables on the two thermal performance criteria, $I_{\text {sum }}$ and $Q_{\text {TоT, }}$, for two different French climates, Nice (Mediterranean climate) and Nancy (continental climate). These two climates were chosen because each is impacted by one-performance criteria more than the other, $I_{\text {sum }}$ for Nice and $Q_{T O T}$ for Nancy. This influence is analyzed with a design of experiments. A presentation of this method can be found in [20]. The four chosen variables are the thermophysical properties of the external walls and of the roof (respectively $k_{\text {wall }}$ and $(\rho c)_{\text {wall }}, k_{\text {roof }}$ and $\left.(\rho c)_{\text {roof }}\right)$. A two-level factorial experimental design assigns the level $(-1)$ to the lowest value of the variables and the level (+1) to their highest value (Table 2), and shows the interactions between these factors.

This technique introduces new reduced dimensionless variables, noted $x_{n}$. A first-degree law is adopted with respect to each variable. For full two-level factorial designs, it is expressed as follows:

Response $=a_{0}+\sum_{n=1}^{p} a_{n} x_{n}$

The dimensional coefficients $a_{n}$ represent the principal effect of each reduced variable on the response, which can be $I_{\text {sum }}$ and $Q_{T O T}$ here. The coefficient $a_{0}$ is the mean value of the response. In order to identify the coefficients $a_{n}$, we need to run $p=2^{4}=16$ simulations, 4 being the number of variables:

$a_{n}=\frac{1}{16} \sum_{p=1}^{16} x_{n}(p) \times \operatorname{response}(p)$

The values of the different principal effects $a_{n}$ for Nice and Nancy are shown in Table 3. Since the impact of the variable is measured by the absolute value of its principal effect, we conclude that the 


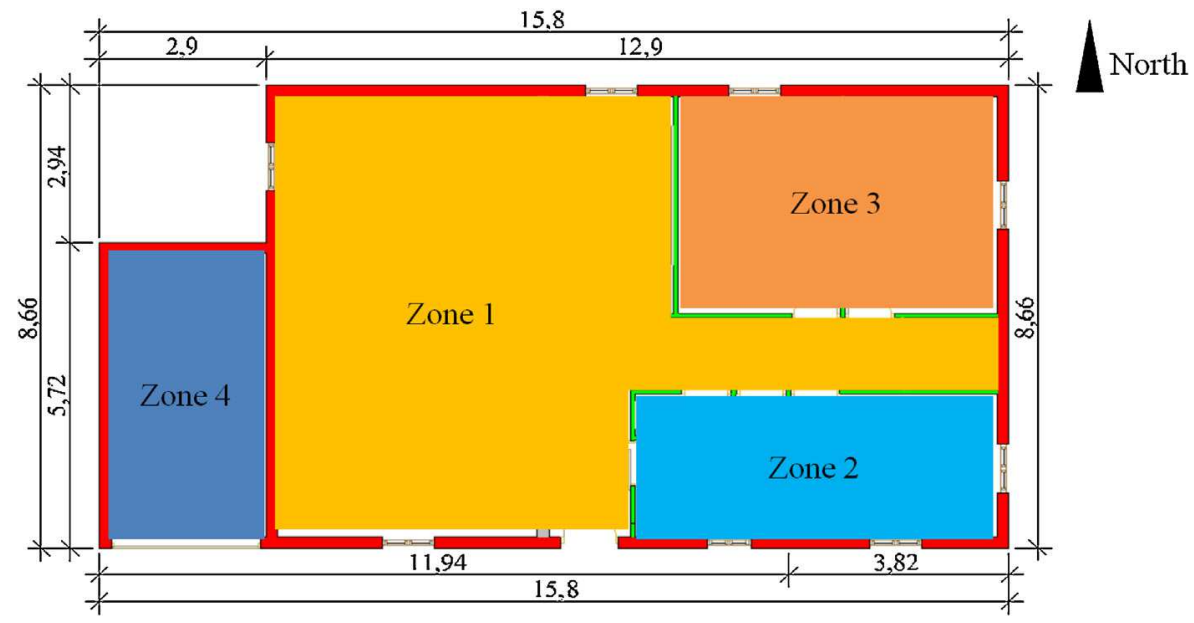

Fig. 2. Residential house blueprint (dimensions in meters).

Table 1

Assumptions and specifications adopted for the thermal simulation of the dwelling.

\begin{tabular}{|c|c|c|c|}
\hline & Parameters & Value & Unit \\
\hline \multirow[t]{9}{*}{ Building } & Location & Nancy, Nice & - \\
\hline & Orientation & South & - \\
\hline & Total indoor surface & 211.02 & $\mathrm{~m}^{2}$ \\
\hline & Total heated volume ( 3 zones) & 197.80 & $\mathrm{~m}^{3}$ \\
\hline & Windows surfaces & 1.08 & $\mathrm{~m}^{2}$ \\
\hline & Windows $U$-value & 2.83 & $W \mathrm{~m}^{-2} \mathrm{~K}^{-1}$ \\
\hline & Windows solar factor & 0.76 & - \\
\hline & Infiltration for non-heated zones & 1 & $\mathrm{ACH}$ \\
\hline & Ventilation for heated zones & 0.6 ( 3 in summer nights) & $\mathrm{ACH}$ \\
\hline \multirow[t]{3}{*}{ Occupation } & Occupancy & 3 & Persons \\
\hline & Occupancy scenario & 17:00-8:00 week days & \\
\hline & & $24 \mathrm{~h} / 24$ week-ends & \\
\hline \multirow[t]{7}{*}{ External envelope } & Indoor plaster thickness & 1 & $\mathrm{~cm}$ \\
\hline & Indoor plaster $k$ & 0.35 & $\mathrm{~W} \mathrm{~m} \mathrm{~m}^{-1} \mathrm{~K}^{-1}$ \\
\hline & Indoor plaster $\rho c$ & 900 & $\mathrm{~kJ} \mathrm{~m}^{-3} \mathrm{~K}^{-1}$ \\
\hline & Insulation thickness & 8 & $\mathrm{~cm}$ \\
\hline & Insulation $k$ & 0.04 & $\mathrm{~W} \mathrm{~m}^{-1} \mathrm{~K}^{-1}$ \\
\hline & Insulation $\rho c$ & 29.4 & $\mathrm{~kJ} \mathrm{~m}^{-3} \mathrm{~K}^{-1}$ \\
\hline & Optimal material thickness (with unknown $k$ and $\rho c$ ) & 20 & $\mathrm{~cm}$ \\
\hline
\end{tabular}

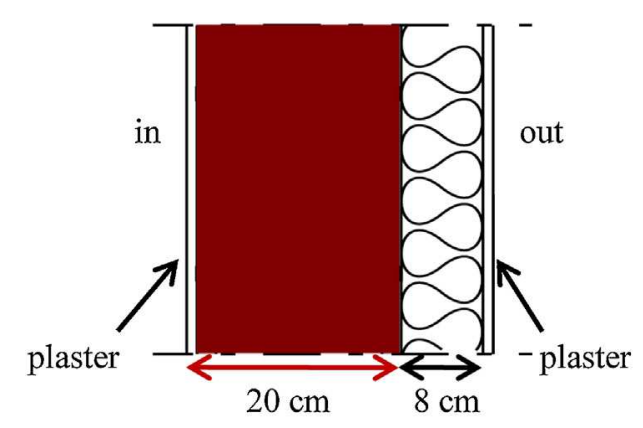

a) Wall

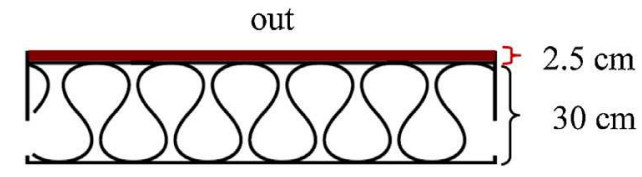

in

b) Roof

Fig. 3. Composition of (a) the external walls (b) the roof.

Table 2

Low and high levels for each parameter.

\begin{tabular}{|c|c|c|c|c|}
\hline & $x_{1}=k_{\text {wall }}\left(\mathrm{W} \mathrm{m}^{-1} \mathrm{~K}^{-1}\right)$ & $x_{2}=k_{\text {roof }}\left(\mathrm{W} \mathrm{m}^{-1} \mathrm{~K}^{-1}\right)$ & $x_{3}=(\rho c)_{\text {wall }}\left(\mathrm{kJ} \mathrm{m}^{-3} \mathrm{~K}^{-1}\right)$ & $x_{4}=(\rho c)_{\text {roof }}\left(\mathrm{kJ} \mathrm{m}^{-3} \mathrm{~K}^{-1}\right)$ \\
\hline-1 & 0.10 & 0.10 & 40 & 40 \\
\hline+1 & 1.75 & 1.75 & 2000 & 2000 \\
\hline
\end{tabular}


Table 3

Principal effects of wall and roof thermophysical properties for Nancy and Nice.

\begin{tabular}{|c|c|c|c|c|c|}
\hline & & $a_{1}\left(k_{\text {wall }}\right)$ & $a_{2}\left(k_{\text {roof }}\right)$ & $a_{3}\left((\rho c)_{\text {wall }}\right)$ & $a_{4}\left((\rho c)_{\text {roof }}\right)$ \\
\hline Nancy & $\begin{array}{l}I_{\text {sum }}\left({ }^{\circ} \mathrm{Ch}\right) \\
Q_{\text {TOT }}\left(\mathrm{kWh} \mathrm{m}^{-2}\right)\end{array}$ & $\begin{array}{r}-17.23 \\
+4.89\end{array}$ & $\begin{array}{l}+0.99 \\
+0.01\end{array}$ & $\begin{array}{r}-97.46 \\
-1.89\end{array}$ & $\begin{array}{l}-3.57 \\
-0.13\end{array}$ \\
\hline Nice & $\begin{array}{l}I_{\text {sum }}\left({ }^{\circ} \mathrm{Ch}\right) \\
Q_{\text {TоT }}\left(\mathrm{kWh} \mathrm{m}^{-2}\right)\end{array}$ & $\begin{array}{r}-302.91 \\
+2.08\end{array}$ & $\begin{array}{l}+9.93 \\
+0.01\end{array}$ & $\begin{array}{r}-512.60 \\
-1.69\end{array}$ & $\begin{array}{r}-26.59 \\
-0.15\end{array}$ \\
\hline
\end{tabular}

volumetric specific heat $(\rho c)$ is the most influent variable on $I_{\text {sum }}$ and the thermal conductivity is the most influent variable on $Q_{T O T}$.

The sign of the principal effects $a_{n}$ gives the variation trends of the responses. For both climates, Table 3 shows that $a_{1}$ and $a_{3}$ for $I_{\text {sum }}$ are preceded by the minus sign. It indicates that the increase of $k_{\text {wall }}$ and $(\rho c)_{\text {wall }}$ leads to a reduction of $I_{\text {sum }}$. Indeed, the summer comfort can be improved by the enhancement of inertia which is related to $(\rho c)_{\text {wall }}[21,22]$, and by more conductive walls that allow to dissipate the heat in summer. The reduction of $Q_{T O T}$ is obtained by the decrease of $k_{\text {wall }}$, underlining the importance of wall insulation, and by the increase of $(\rho c)$ which emphasizes the advantage of inertia.

The impact of the roof on both $I_{\text {sum }}$ and $Q_{T O T}$ is not of the same order of magnitude as the external walls. For Nancy, $k_{\text {wall }}$ has over 500 times more influence on $Q_{\text {TOT }}$ than $k_{\text {roof }}$, and 17 times more influence on $I_{\text {sum }}$ (Table 3 ). This is due to the low thickness of roof material to optimize $(2.5 \mathrm{~cm})$ in comparison to the external walls' one $(20 \mathrm{~cm})$. Thus, for the remainder of this study, we will perform the optimization with only $k_{\text {wall }}$ and $(\rho c)_{\text {wall }}$.

\subsection{Description of the ANN}

\subsubsection{Parameters for the ANN}

Prior to training the neural network, all input variables and objective-functions are linearly scaled to a range of -1 to +1 in order to ease the training process. In our work, the ANN is composed of 4 layers of neurons. There are 15 neurons in the first layer, 11 neurons in the second layer, 7 neurons for the third layer, and 3 neurons in the fourth layer. As we have seen in (2.3), neurons need transfer functions in order to compute their output. It is common to choose a hyperbolic tangent sigmoid transfer function for the hidden layers (the first, second and third layers) and a linear transfer function for output layer (the fourth layer).

\subsubsection{Training of the ANN}

The Levenberg-Marquardt back propagation method is used to compute the weight values of the ANN. This training method updates the network weights in the direction in which the training performance function decreases most rapidly. The training performance is determined by the mean squared error (MSE) and it is stopped when MSE reaches $1 \times 10^{-7}$.

\subsubsection{Validation of the ANN}

In order to check the accuracy of the ANN to predict $I_{\text {sum }}$ and $Q_{\text {TOT }}, 25$ samples are randomly selected and the corresponding $I_{\text {sum }}$ and $Q_{\text {TOT }}$ from TRNSYS are compared to data issued from the ANN. The maximum deviations for $I_{\text {sum }}$ and $Q_{\text {TOT }}$ are $1.86 \%$ and $0.22 \%$ for Nancy, and are $0.19 \%$ and $0.04 \%$ for Nice. These low values confirm the accuracy of the ANN.

\subsection{Optimization results and discussion}

\subsubsection{Optimization results}

Many numerical computations performed previously by the present authors have shown that convergence tends to be difficult when sampling numbers are limited (i.e. the number of individuals in a population), or when too small of a crossover probability is
Table 4

Values associated to the points A, B, C, D, A', B', $\mathrm{C}^{\prime}$ and $\mathrm{D}^{\prime}$ in Figs. 4 and 5.

\begin{tabular}{|c|c|c|c|c|c|}
\hline & & $\begin{array}{l}k_{\text {wall }} \\
\left(\mathrm{W} \mathrm{m}^{-1} \mathrm{~K}^{-1}\right)\end{array}$ & $\begin{array}{l}(\rho c)_{\text {wall }} \\
\left(\mathrm{kJ} \mathrm{m}^{-3} \mathrm{~K}^{-1}\right)\end{array}$ & $Q_{\text {тот }}\left(\mathrm{kWh} \mathrm{m}^{-2}\right)$ & $I_{\text {sum }}\left({ }^{\circ} \mathrm{Ch}\right)$ \\
\hline \multirow[t]{4}{*}{ Nancy } & A & 0.10 & 1727 & 32.3 & 49 \\
\hline & B & 0.10 & 1587 & 37.2 & 30 \\
\hline & $\mathrm{C}$ & 0.16 & 1540 & 48.5 & 23 \\
\hline & $\mathrm{D}$ & 1.75 & 2000 & 56.1 & 2 \\
\hline \multirow[t]{4}{*}{ Nice } & $A^{\prime}$ & 0.27 & 1892 & 13.9 & 1831 \\
\hline & $\mathrm{B}^{\prime}$ & 0.31 & 2000 & 14.1 & 1751 \\
\hline & $\mathrm{C}^{\prime}$ & 1.03 & 2000 & 16.9 & 1567 \\
\hline & $\mathrm{D}^{\prime}$ & 1.75 & 2000 & 17.2 & 1503 \\
\hline
\end{tabular}

chosen. The NSGA-II needs some parameters based on two main genetic operators: crossover and mutation. One hundred individuals, i.e. envelopes characterized by $(k, \rho c)$, per population lead to a satisfactory convergence calculation. The maximum generation number, here 500 , is the stopping criterion because in previous numerical tests, we have verified that the solutions did not change beyond this number. The NSGA-II algorithm uses simulated binary crossover with a crossover probability of 90\% (90 envelopes in a population exchange $(k, \rho c)$ with others). The mutation probability is set to $25 \%$ ( 25 envelopes in a population are randomly changed).

Once we have an efficient ANN and a well-set NSGA-II algorithm, we can perform the optimization. Figs. 4 and 5 show Pareto fronts that are composed of well-spread optimal solutions.

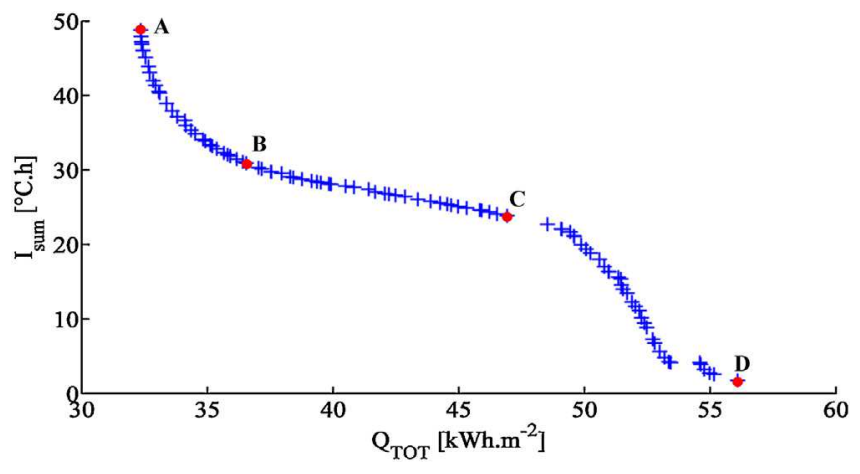

Fig. 4. $I_{\text {sum }}$ as a function of $Q_{\text {Tот }}$ (Nancy).

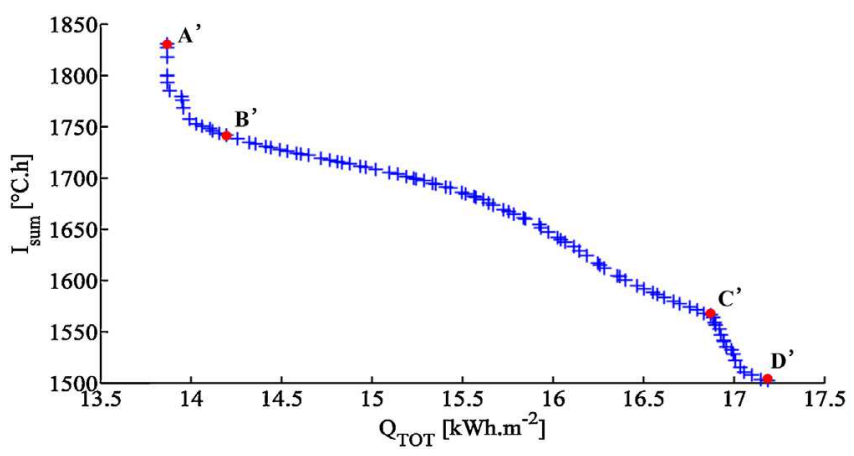

Fig. 5. $I_{\text {sum }}$ as a function of $Q_{\text {TOT }}$ (Nice). 


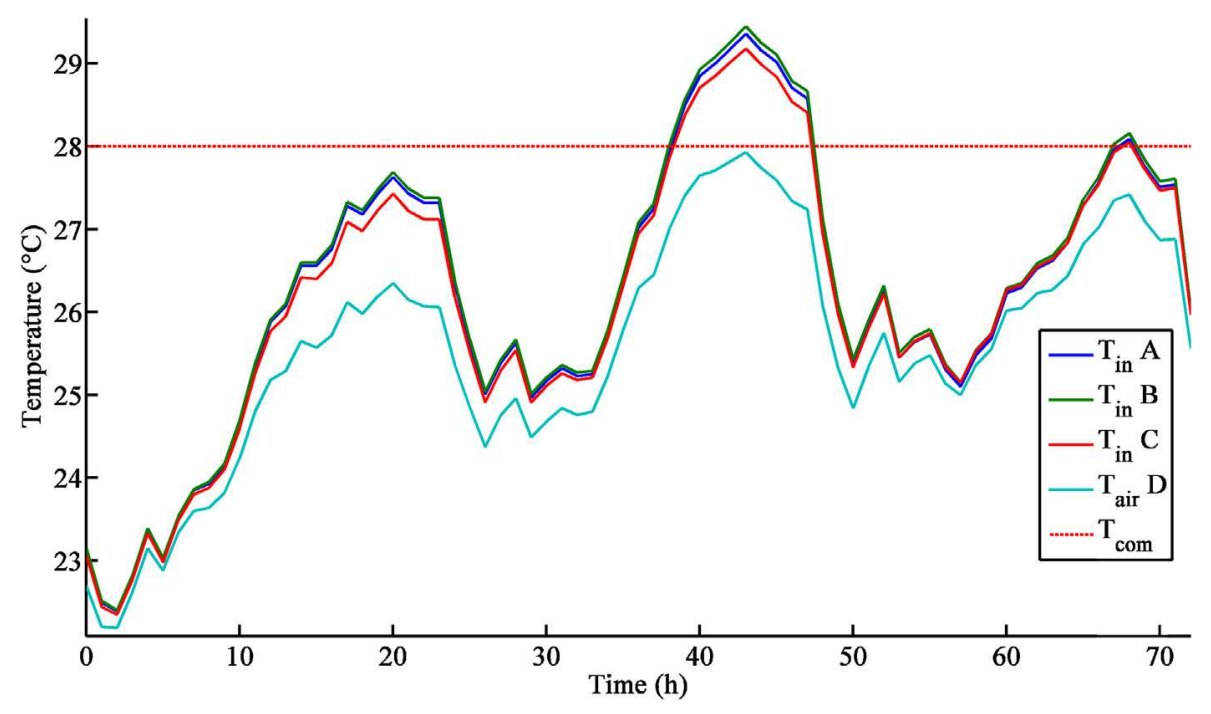

Fig. 6. Evolution of $T_{\text {in }}$ for 4 optimal residential buildings (Nancy).

The first part ( $A$ to B and $\mathrm{A}^{\prime}$ to $\mathrm{B}^{\prime}$ ) corresponds to a steep fall of $I_{\text {sum }}$ for lower values of $Q_{T O T}$. Indeed, the most insulated external walls (low values of $k_{\text {wall }}$ ) are the optimal solutions and summer comfort is significantly degraded because heat cannot be sufficiently dissipated to the outside.

The second part ( $B$ to $C$ and $B^{\prime}$ to $C^{\prime}$ ) is almost linear. The slope of this part of the Pareto front is greater for Nice than for Nancy. For both climates, the decrease of $I_{\text {sum }}$ is mainly due to the rise of $k_{\text {wall }}$ (Table 4).

The third part ( $\mathrm{C}$ to $\mathrm{D}$ and $\mathrm{C}^{\prime}$ to $\mathrm{D}^{\prime}$ ) corresponds to a sharp fall of $I_{\text {sum }}$ for higher values of $Q_{\text {TOT }}$.

Table 4 indicates that the optimal materials have $(\rho c)_{\text {wall }}$ close or equal to the highest value of $(\rho c)_{\text {wall }}$, i.e. $2000 \mathrm{~kJ} \mathrm{~m}^{-3} \mathrm{~K}^{-1}$. Table 3 provides the explanation: $a_{3}$ is always negative for both objectivefunctions and climates, demonstrating that the increase of $(\rho c)_{\text {wall }}$ corresponds to a decrease of $I_{\text {Sum }}$ and $Q_{T O T}$. We can also notice that in Nancy, the energy reduction problem should be resolved in priority because of small values of $I_{\text {sum }}$. In Nice, it is the thermal comfort problem that should be addressed first because of low values of $Q_{\text {TOT. }}$

\subsubsection{Analysis of the dynamic thermal comportment in summer}

In Nancy, optimal values of $I_{\text {sum }}$ are close to one another and low (Table 4): this is the reason why we will analyze more finely the dynamic thermal behavior in summer. Fig. 6 shows the time evolution of the indoor temperature of zone 1 of the dwelling whose external walls are composed of different optimal materials A, B, C and $\mathrm{D}$ (Table 4), during 3 days (20,21 and 22 July, the warmest days of the year) for Nancy. $I_{\text {sum }}$ can be represented graphically as the computed surface between the time evolution curve of $T_{\text {in }}$ and $T_{\text {com }}$ when $T_{\text {in }}$ is above $T_{\text {com }}$. Thus, we observe that the curves A and B

\subsubsection{Comparison between different optimization methods}

In order to discuss the efficiency of the methodology used in this article, we are going to compare our results with those obtained from other commonly used optimization methods found in literature. They consist in coupling two distinct tools: a thermal simulation program that computes thermal performance criteria and an optimization program for the minimization of cost functions that are evaluated by the thermal simulation program. Contrary to the methodology involving the ANN described above, the cost function is evaluated exactly by the thermal simulation program. GenOpt [18], mentioned above, is also an optimization tool that can be coupled with external software such as TRNSYS in our case. It proposes global multi-dimensional optimization algorithms for linear cost functions. In our work, a particle swarm optimization (PSO) algorithm is used in order to perform the optimization. Several studies involving the use of GenOpt in building energy optimizations have been performed and have demonstrated its efficiency [23-25]. GenOpt deals with mono-objective optimization problems. The two methods we are going to compare are the aggregative method and penalty function method.

The aggregative method combines both objective functions $Q_{T O T}$ and $I_{\text {sum }}$ into a weighted-sum $f$ :

$\left\{\begin{array}{l}\min f=\frac{1}{2}\left(\frac{I_{\text {sum }}-I_{\text {sum }}^{\min }}{I_{\text {sum }}^{\max }-I_{\text {sum }}^{\min }}\right)+\frac{1}{2}\left(\frac{Q_{T O T}-Q_{T O T}^{\min }}{Q_{T O T}^{\max }-Q_{T O T}^{\min }}\right) \\ k_{\text {wall }} \in[0.1 ; 1.75] \\ (\rho c)_{\text {wall }} \in[40 ; 2000]\end{array}\right.$

where

$$
\begin{aligned}
& I_{\text {sum }}^{\max }=140^{\circ} \mathrm{Ch}, I_{\text {sum }}^{\min }=2{ }^{\circ} \mathrm{Ch}, Q_{T O T}^{\max }=65.4 \mathrm{kWh} \mathrm{m}^{-2}, Q_{T Q T}^{\min }=50.6 \mathrm{kWh} \mathrm{m}^{-2} \text { for Nancy } \\
& I_{\text {sum }}^{\max }=3155^{\circ} \mathrm{Ch}, I_{\text {sum }}^{\min }=1503^{\circ} \mathrm{Ch}, Q_{T O T}^{\max }=20.8 \mathrm{kWh} \mathrm{m}^{-2}, Q_{T O T}^{\min }=13.7 \mathrm{kWh} \mathrm{m}^{-2} \text { for Nice }
\end{aligned}
$$

are almost identical, which means that the optimal solutions $A$ and $B$ are nearly equivalent in terms of dynamic thermal behavior. The amplitude of the curve $C$ is lower than those of the curves $A$ and $\mathrm{B}$, which actually leads to a lower value of $I_{\text {sum. }}$. The curve D has its amplitude more flattened than those of the three other curves; it is even below $T_{\text {com }}$ on the period considered.
The above minimum and maximum values of $I_{\text {sum }}$ and $Q_{\text {TOT }}$ are obtained from different combinations of range limits of the variables $k_{\text {wall }}$ and $(\rho c)_{\text {wall }}$. These combinations are given in Table 5.

In the penalty function method, we impose a constraint on $I_{\text {sum }}$, which is formulated by an inequality. In practice, a penalty term is added to $Q_{T O T}$ : every time the constraint is violated, a large positive 
Table 5

Parameters $I_{\text {sum }}$ and $Q_{T O T}$ for mono-objective optimizations (Eqs. (4) and (5)).

\begin{tabular}{|c|c|c|c|c|c|c|}
\hline & $k_{\text {wall }}\left(\mathrm{W} \mathrm{m}^{-1} \mathrm{~K}^{-1}\right)$ & $(\rho c)_{\text {wall }}\left(\mathrm{kJ} \mathrm{m}^{-3} \mathrm{~K}^{-1}\right)$ & $I_{\text {sum }}^{\max }\left({ }^{\circ} \mathrm{Ch}\right)$ & $I_{\text {sum }}^{\min }\left({ }^{\circ} \mathrm{Ch}\right)$ & $Q_{\text {TOT }}^{\max }\left(\mathrm{kWh} \mathrm{m}^{-2}\right)$ & $Q_{\text {TOT }}^{\min }\left(\mathrm{kWh} \mathrm{m}^{-2}\right)$ \\
\hline \multirow[t]{4}{*}{ Nancy } & 0.1 & 40 & 140 & & & \\
\hline & 1.75 & 2000 & & 2 & & \\
\hline & 1.75 & 40 & & & 65.4 & \\
\hline & 0.1 & 2000 & & & & 50.6 \\
\hline \multirow[t]{4}{*}{ Nice } & 0.1 & 40 & 3155 & & & \\
\hline & 1.75 & 2000 & & 1503 & & \\
\hline & 1.75 & 40 & & & 20.8 & \\
\hline & 0.1 & 2000 & & & & 13.7 \\
\hline
\end{tabular}

Table 6

Comparison of optimal results between aggregative method (Ag.) and penalty functions (Pe.).

\begin{tabular}{|c|c|c|c|c|c|c|c|c|}
\hline & \multicolumn{2}{|c|}{$k_{\text {wall }}\left(\mathrm{Wm}^{-1} \mathrm{~K}^{-1}\right)$} & \multicolumn{2}{|c|}{$(\rho c)_{\text {wall }}\left(\mathrm{kJ} \mathrm{m}^{-3} \mathrm{~K}^{-1}\right)$} & \multicolumn{2}{|c|}{$Q_{\text {TOT }}\left(\mathrm{kWh} \mathrm{m}^{-2}\right)$} & \multicolumn{2}{|c|}{$I_{\text {sum }}\left({ }^{\circ} \mathrm{Ch}\right)$} \\
\hline & Ag. & Pe. & Ag. & Pe. & Ag. & Pe. & Ag. & Pe. \\
\hline Nancy & 0.10 & 0.10 & 2000 & 2000 & 50.6 & 50.6 & 13 & 13 \\
\hline Nice & 0.10 & 1.75 & 2000 & 2000 & 13.7 & 17.2 & 2298 & 1503 \\
\hline
\end{tabular}

number is added to $Q_{\text {TOT }}$. Such a procedure taking into account the constraint by penalty function is already implemented in GenOpt.

$$
\left\{\begin{array}{l}
\min Q_{\text {TOT }} \\
I_{\text {sum }} \leq I_{\text {sum }}^{\min } \\
k_{\text {wall }} \in[0.1 ; 1.75] \\
(\rho c)_{\text {wall }} \in[40 ; 2000]
\end{array}\right.
$$

Table 6 summarizes the optimization results obtained both by the aggregative method and penalty function.

The results in Table 6 belong to the third part of Pareto fronts (high $Q_{T O T}$ and low $I_{\text {sum }}$ ) for both climates, except for the Nice optimal values from aggregative method which do not appear in the Pareto front. It is important to note that aggregative method and penalty functions produce completely opposite results for Nice (aggregative: $k_{\text {wall }}=0.10 \mathrm{~W} \mathrm{~m}^{-1} \mathrm{~K}^{-1}$, penalty: $\left.k_{\text {wall }}=1.75 \mathrm{~W} \mathrm{~m}^{-1} \mathrm{~K}^{-1}\right)$. Indeed, $I_{\text {sum }}$ gives the main direction to the optimization process using the aggregative method because the principal effects of $k_{\text {wall }}$ and $(\rho c)_{\text {wall }}$ on $I_{\text {sum }}$ (which are both negative) are higher than those of $Q_{T O T}$ (Table 3 ). However, the penalty function drives the optimization process to take low values of $I_{\text {sum }}$, which implies that $k_{\text {wall }}$ is set to its highest value.

To conlude on the comparison between these different optimization methods, mono-objective optimization using the aggregative method or the constraint problem in GenOpt is too sensitive to privileged directions, especially in our case where the objective functions have different ranges of variation speed. Moreover, the mono-objective optimization only provides one solution which is relatively restrictive, and does not allow choosing among optimal solutions as the multi-optimization does.

\section{Conclusion}

This work presents a methodology for building envelope optimization in terms of thermal performance. In order to reduce the computation time without reducing the complexity of the problem, an artificial neural network has been developed: its role is to provide fast and accurate evaluations of objective functions which are used by a genetic algorithm. The efficiency of this methodology has been proven by applying it to a residential house for two French climates, Nancy (continental) and Nice (Mediterranean). Two objective functions have been considered as being representative of energy performance: the annual energy load $Q_{T O T}$ and the summer comfort index $I_{\text {sum }}$. Thermophysical properties of the external walls, $k_{\text {wall }}$ and $(\rho c)_{\text {wall }}$, have been chosen as optimization variables.

A design of experiments has been conducted to quantify the impact of the variables $k_{\text {wall }}$ and $(\rho c)_{\text {wall }}$ on the objective functions $Q_{T O T}$ and $I_{\text {sum }}$. The optimal solutions are presented as Pareto fronts for the two climates. These optimal solutions cover the entire range of possible solutions. They enable the selection of the thermophysical properties according to the conflicting objective functions. These multi-objective optimization results have been compared to those from mono-objective optimization by using an aggregative method and a constraint problem in GenOpt. The comparison clearly shows the advantage of performing multi-objective optimization since it ensures that the optimization is not trapped in a privileged direction.

This study also highlights the major influence of the climate on optimal envelopes. Indeed, we have shown that the optimal solutions are very different for various climates. However, standard building solutions do not adequately take into account this parameter as they are often identical for any climate.

\section{Acknowledgements}

The authors thank the French Environment and Energy Management Agency (ADEME) and the Technical Center for Natural Building Materials (CTMNC) for their support.

\section{References}

[1] International Energy Agency, Electricity/Heat in France, 2009, http://www.iea.org/stats/electricitydata.asp?COUNTRY_CODE=FR (14.05.13).

[2] D. Tuhus-Dubrow, M. Krarti, Genetic-algorithm based approach to optimize building envelope design for residential buildings, Building and Environment 45 (2010) 1574-1581.

[3] L. Magnier, F. Haghighat, Multiobjective optimization of building design using TRNSYS simulations, genetic algorithm, and Artificial Neural Network, Building and Environment 45 (2010) 739-746.

[4] J. Yang, H. Rivard, R. Zmeureanu, On-line building energy prediction using adaptive artificial neural networks, Energy and Buildings 37 (2005)1250-1259.

[5] M. Anstett, J.F. Kreider, Application of neural networking models to predict energy use, ASHRAE Transactions 99 (1993) 505-517.

[6] P.S.Curtiss, J.F. Kreider, M.J. Brandemuehl, Energy management in central HVAC plants using neural networks, ASHRAE Transactions 100 (1994) 476-493.

[7] A.M. Omer, Energy, environment and sustainable development, Renewable Sustainable Energy Reviews 12 (2008) 2265-2300.

[8] B. Lartigue, B. Lasternas, V. Loftness, Multi-objective optimization of building envelope for energy consumption and daylight, Indoor and Built Environment (2013), doi:1420326X13480224.

[9] Thermal regulations for buildings 2010 (in French), CSTB Editions, Paris, France, 2010.

[10] P.O. Fanger, Thermal Comfort, Robert E. Krieger Publishing Company, Malabar, FL, USA, 1982 
[11] J.F. Nicol, M.A. Humphreys, Adaptive thermal comfort and sustainable thermal standards for buildings, Energy and Buildings 34 (2002) 563-572.

[12] R.J. de Dear, G.S. Brager, Thermal comfort in naturally ventilated buildings: revisions to ASHRAE Standard 55, Energy and Buildings 34 (2002) $549-561$.

[13] Y.Zhang, K. Lin, Q. Zhang, H. Di, Ideal thermophysical properties for free-cooling (or heating) buildings with constant thermal physical property material, Energy and Buildings 38 (2006) 1164-1170.

[14] V. Sambou, B. Lartigue, F. Monchoux, M. Adj, Thermal optimization of multilayered walls using genetic algorithms, Energy and Buildings 41 (2009) 1031-1036.

[15] K. Deb, A. Pratap, S. Agarwal, T.A. Meyarivan, Fast elitist multiobjective genetic algorithm: NSGA-II, IEEE Transactions on Evolution Computation 6 (2002) 182-197.

[16] W.S. McCulloch, W. Pitts, A logical calculus of the ideas immanent in nervous activity, The Bulletin of Mathematical Biophysics 5 (1943) 115-133.

[17] TRNSYS 16 - A TRaNsient SYstem Simulation Program - Manual, Solar Energy Laboratory, University of Wisconsin, 2004.

[18] M. Wetter, GenOpt, Generic Optimization program, User manual, version 3.0.0. Berkeley Lawrence Berkeley National Laboratory, 2008.
[19] CSTB, Inertie thermique des logements et confort d'été: Etude de sensibilité, Collection technique Cimbéton, Paris, France, 2001.

[20] J. Goupy, Design of Experiments Method (in French), Dunod, Paris, France 1988.

[21] S.C. Ng, K.S. Low, N.H. Tioh, Newspaper sandwiched aerated lightweight concrete wall panels - thermal inertia, transient thermal behavior and surface temperature prediction, Energy and Buildings 43 (2011) 1636-1645.

[22] D.K. Serghides, C.G. Georgakis, The building envelope of Mediterranean houses: optimization of mass and insulation, Journal of Building Physics 36 (2012) 83-98.

[23] B. Coffey, F. Haghighat, E. Morofsky, E. Kutrowski, A software framework for model predictive control with GenOpt, Energy and Buildings 42 (2010) 1084-1092.

[24] L. Stephan, A. Bastide, E. Wurtz, B. Souyri, Ensuring desired natural ventilation rate by means of optimized openings, in: Proc. of the 11th IBPSA Conference 2009, 2009.

[25] E. Asadi, M.G. da Silva, C.H. Antunes, L. Dias, A multi-objective optimization model for building retrofit strategies using TRNSYS simulations, GenOpt and MATLAB, Building and Environment 56 (2012) 370-378. 